\title{
Ammonia synthesis fundamentals for a model-based HAZOP study
}

\author{
Ján Janošovský, Juraj Labovský, L’udovít Jelemenský \\ Institute of Chemical and Environmental Engineering, \\ Slovak University of Technology, Bratislava \\ ludovit.jelemensky@stuba.sk
}

\begin{abstract}
Hazard and operability (HAZOP) analysis is a highly disciplined process hazard analysis (PHA) technique based on the exploration of the effects of process variables deviations. Inconveniences of a conventional HAZOP study are its time-consuming character and high cost. The principal objective of this paper is to present a new methodology for hazard identification of a selected chemical production process. Model-based HAZOP study is a very robust tool for predicting a systems response to deviations from design or operation conditions. An approach based on the mathematical modelling of a process can help to identify sources of hazard that could be overlooked by conventional PHA techniques. A case study focused on the multiple steady states phenomenon in an ammonia synthesis reactor is presented. The process simulation was performed using the Aspen HYSYS v8.4 process modelling environment. Nonlinear behaviour of the investigated fixed-bed reactor system was confirmed by an accident in an industrial ammonia synthesis reactor. The analysed system exhibited the feed temperature and pressure dependence of various operation parameters. This fact indicates the presence of multiple steady states. From the safety analysis point of view, switching between steady states can lead to process hazards.
\end{abstract}

Keywords: model-based process hazard analysis, HAZOP study, ammonia synthesis, nonlinear behaviour

\section{Introduction}

Loss prevention has become a more important and systematic field in process industry in the last 40 years mainly thanks to tri-annual symposia starting with the initial symposium "Major Loss Prevention in the Process Industries" held in Newcastle in 1971 and ending with the forthcoming 14th "Loss Prevention" symposium in Freiburg, Germany in 2016 (De Rademaeker et al., 2014). During the last decade chemical industry has undergone a considerable change. The requirement of higher yields was caused by economic pressure. This led to the modification of chemical processes towards extreme high (low) temperatures and pressures. Under these conditions, process safety becomes an even more urgent problem to be solved. Hazard and operability study (HAZOP) is one of the most often used and highly efficient techniques for the identification of hazard not only in chemical industry. HAZOP analysis is a highly disciplined procedure based on combinations of guide words and process variables. When the guide word (more, less, no...) is applied to a process variable, a deviation is generated. The next step in the HAZOP study is to monitor the causes, propagation and consequences of process variable deviations. The HAZOP report represents a list of all deviations, their causes and consequences, analysis of such consequences, current level of protection and recommended actions. The use of HAZOP is successful in safety analysis not only in the operation phase of existing plants but also in the design of new ones (Kletz, 1997).

The lack of time and experiences of human expert teams are often the main problem in a HAZOP execution. The most frequently proposed solution of this problem is automation of "hazoping". A literature review presented by Dunjó et al. (2010) indicated that approximately $40 \%$ of the total publications in the field of HAZOP research is related to expert systems for HAZOP automation. The advantages of an automated HAZOP analysis tool are reduced requirements for time and effort. There are two possible approaches: knowledgebased and model-based. Typical knowledge-based expert systems, i.e. systems using a knowledge base containing information about the failure mode, causes and consequences of various process units and/or pieces of equipment, are presented in publications of Venkatasubramanian et al. (1994), Khan et al. (1997), Srinivasan et al. (1997) and Kang et al. (1999).

The knowledge-based approach has one significant disadvantage: in the age of constant development of technology and pushing the limits of process variables to extreme values, it is questionable, if the identification of all possible hazardous events is possible using only large databases of experience. That is the reason, why the model-based approach has gained more importance. Advantages of the use of mathematical modelling in safety analysis are presented by Labovský et al. (2007). 
The model-based HAZOP study is based on the implementation of a detailed mathematical model of a chemical process. The conventional HAZOP study does not consider the duration and value of the deviations. These problems can be examined thanks to the model-based HAZOP approach. Typical model-based expert systems employ MATLAB ${ }^{\circledR}$ for educational purposes (Eizenberg et al., 2006) as well as for real process safety analyses, e.g. using steady-state analysis and dynamic simulation for a real MTBE chemical plant (Labovský et al., 2007) or using process simulation performed by the industrial simulation package Aspen Plus ${ }^{\circledR}$ version 2006.5 for continuous biodiesel production (Jeerawongsuntorn et al., 2011).

The aim of this work is to propose the application of the Aspen HYSYS v8.4 process modelling in process hazard analysis. Ammonia synthesis was chosen as the case study. This chemical process was chosen because of its strong nonlinear behaviour. In the first step, kinetics of reaction were taken from literature and implemented in Aspen HYSYS v8.4. The next step was the generation of deviations and the analysis of the response of the examined system. This analysis was performed using Aspen HYSYS models and an external program created in the $\mathrm{C} \#$ language. Finally, results of the process analysis were processed applying the principles of a HAZOP study. It is necessary to point out that the investigation of the chosen systems is strongly dependent on the selection of an appropriate mathematical model and parameters describing their physical properties, reaction kinetics etc.

\section{Case study}

The presented safety analysis is demonstrated on the case study of ammonia production. Ammonia synthesis takes place in a fixed-bed reactor system which is schematically shown in Fig. 1. The reactor system consists of three beds in series with fresh feed quenching between each bed because of adjusting the optimal temperature profile. Ammonia is produced according to the following reaction scheme:

$$
\mathrm{N}_{2}+3 \mathrm{H}_{2}=2 \mathrm{NH}_{3}
$$

where the reaction rate is given by Froment and Bischoff (1990). An internal Aspen HYSYS v8.4 library was used to calculate the physicochemical properties of all pure components and the mixed physicochemical properties, and the Peng-Robinson equation of state was selected as the property package. The design operation parameters are set as follows in Table 1. The main function of the heat exchanger is to preheat the feed with the outlet stream from the fixed-bed reactor (outlet bed 3). A simple end point was selected in the Aspen HYSYS v8.4 Heat Exchanger Model. Overall heat transfer coefficient was calculated to achieve similar behaviour of the preheater as presented by Morud and Skogestad (1998), where the heat exchanger provides a relationship in the form:

$$
T_{\text {inlet bed } 1}=0.629 \times T_{\text {outlet bed } 3}+0.371 \times T_{\text {fresh feed }}
$$

where $T_{\text {inlet bed } 1}$ is the reactor inlet (preheater outlet) temperature, $T_{\text {outlet bed } 3}$ the reactor outlet temperature

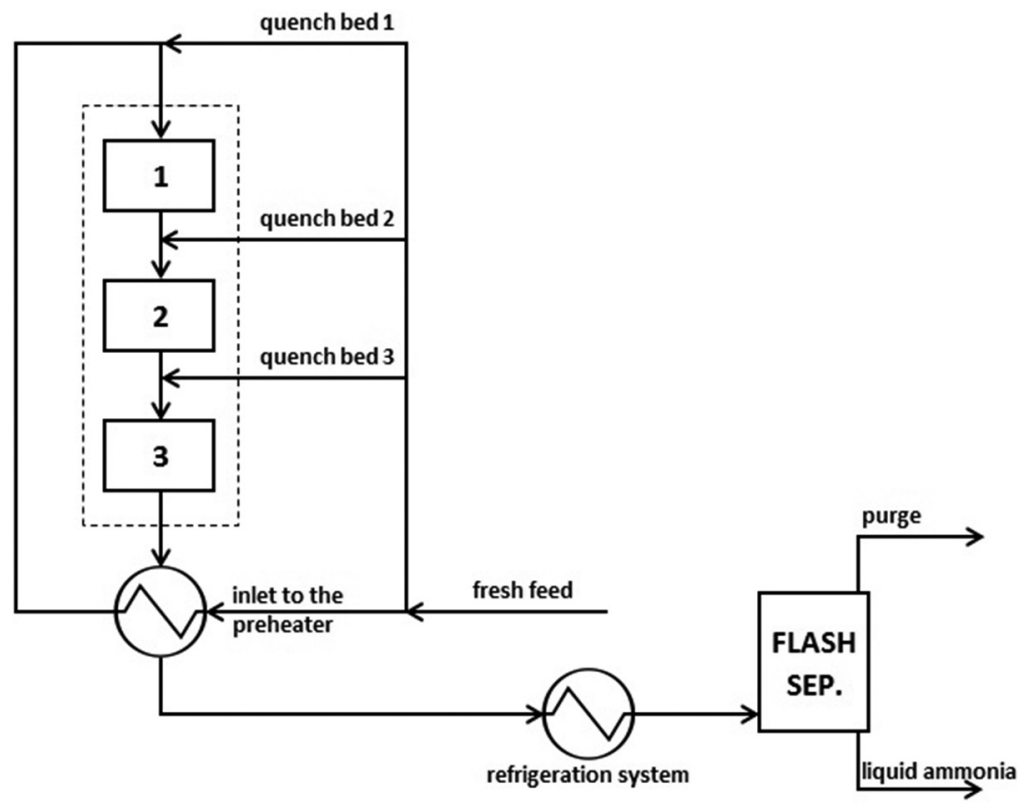

Fig. 1. Schematic description of the reactor system. 
Tab. 1. Design operation parameters.

\begin{tabular}{lcccccc}
\hline Stream & $\begin{array}{c}\text { Mass flow } \\
{\left[\mathbf{1 0}^{\mathbf{3}} \mathbf{~} \mathbf{g} / \mathbf{h}\right]}\end{array}$ & $\begin{array}{c}\text { Temperature } \\
{\left[{ }^{\circ} \mathbf{C}\right]}\end{array}$ & $\begin{array}{c}\text { Pressure } \\
{[\mathbf{M P a}]}\end{array}$ & $\begin{array}{c}\text { Mole fraction } \\
\mathbf{N H}_{\mathbf{3}}\end{array}$ & $\begin{array}{c}\text { Mole fraction } \\
\mathbf{N}_{2}\end{array}$ & \multicolumn{2}{c}{ Mole fraction } \\
\hline fresh feed & 252 & 250 & 20 & 0.04 & 0.24 & 0.72 \\
quench bed 1 & 58 & 250 & 20 & 0.04 & 0.24 & 0.72 \\
quench bed 2 & 35 & 250 & 20 & 0.04 & 0.24 & 0.72 \\
$\begin{array}{l}\text { quench bed 3 } \\
\text { inlet to heat }\end{array}$ & 32 & 250 & 20 & 0.04 & 0.24 & 0.72 \\
exchanger & 127 & 250 & 20 & 0.04 & 0.24 & 0.72 \\
outlet bed 1 & 185 & 520 & 20 & 0.14 & 0.22 & 0.64 \\
outlet bed 2 & 220 & 530 & 20 & 0.16 & 0.21 & 0.63 \\
outlet bed 3 & 252 & 525 & 20 & 0.17 & 0.21 & 0.62 \\
inlet refrigera- & 252 & 436 & 20 & 0.17 & 0.21 & 0.62 \\
tion system & 202 & 8 & 20 & 0.06 & 0.23 & 0.71 \\
purge & 50 & 8 & 20 & 0.98 & 0.00 & 0.02 \\
liquid ammonia & & & & & & \\
\hline
\end{tabular}

and $T_{\text {fresh feed }}$ the temperature of the fresh feed. In the refrigeration system, the heat exchanger outlet is cooled to the temperature of $8{ }^{\circ} \mathrm{C}$. In the flash separator, the refrigeration system outlet is separated to the liquid and gaseous phase. The pressure drop for individual equipment was not taken into account.

\section{Results and Discussion}

A typical process variable deviation created by a conventional HAZOP study would be a combination of the guide word "less" or "more" and the process variable "temperature" resulting in "lower temperature" or "higher temperature" than a design value. The design operation feed temperature is $250^{\circ} \mathrm{C}$ in this case study. Fig. 2 shows the effect of the fresh feed temperature change on the hydrogen conversion. It is evident that the steady state solution diagram exhibits two steady state conversions in the range of $220-270{ }^{\circ} \mathrm{C}$ and that the design operation temperature is located at the branch of the high steady state conversions in the region of multiplicity. From Fig. 2 it follows that in case when the feed temperature control failure causes the fresh feed temperature increase, the HAZOP deviation "higher temperature", the overall hydrogen conversion gradually decreases. On the other hand, when the feed temperature control failure causes the fresh feed temperature decrease of $10 \%$, the HAZOP deviation "lower temperature", to $225^{\circ} \mathrm{C}$, a gradual increase of the hydrogen conversion occurs.

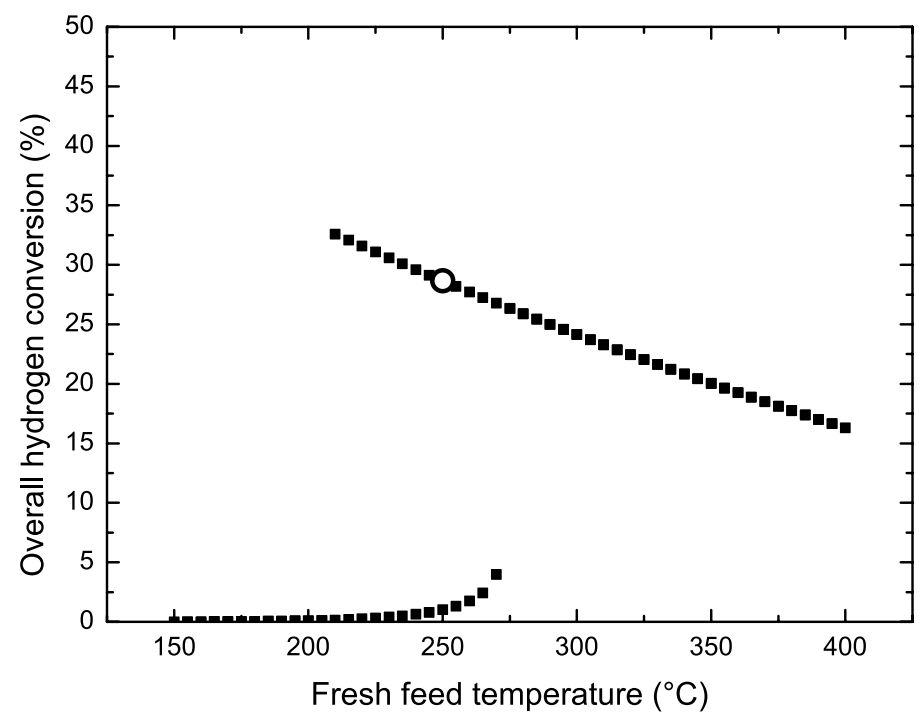

Fig. 2. Hydrogen conversion in the reactor system as a function of the fresh feed temperature (circle - design operating point). 

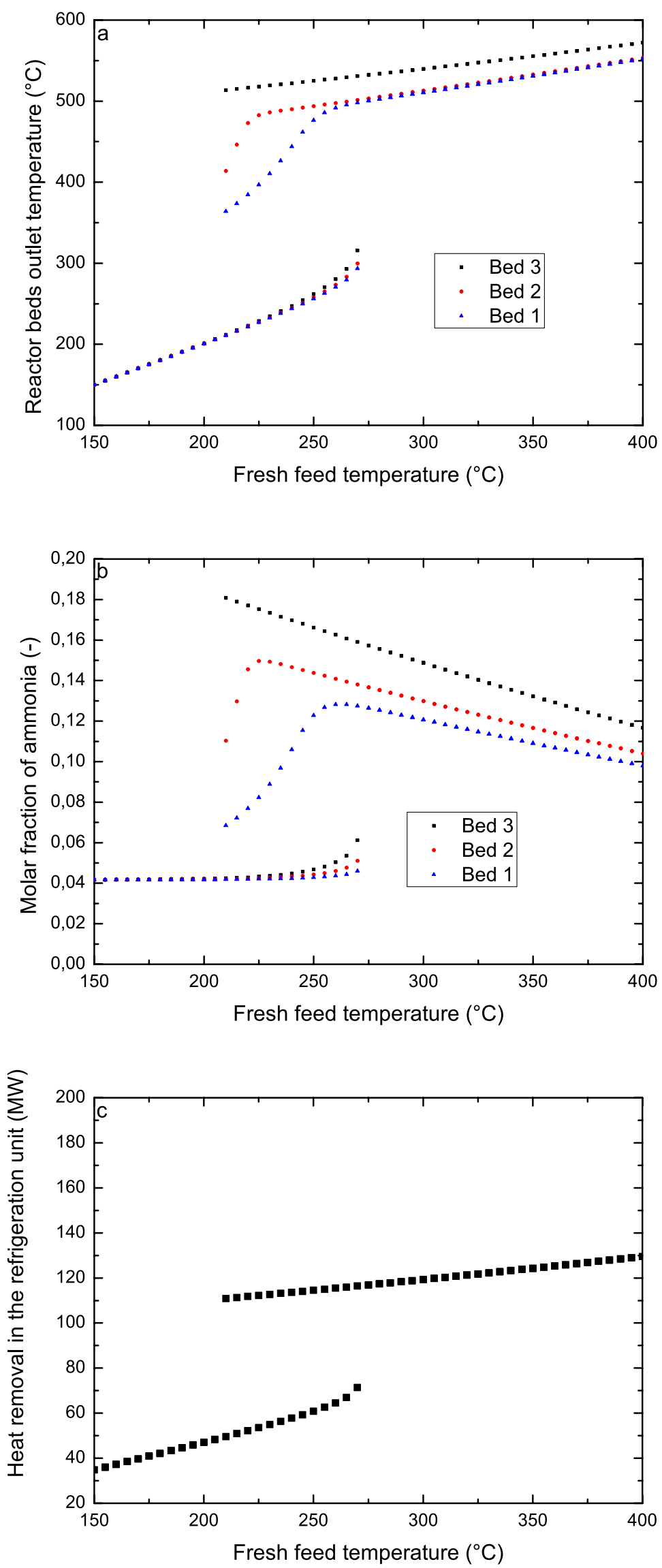

Fig. 3. Operation process variables dependence on the fresh feed temperature - reactor beds outlet temperature (a), molar fraction of ammonia in the beds outlet streams (b), required heat removal in the refrigeration system (c) (triangles - bed 1, circles - bed 2, squares - bed 3). 
However, in case of a failure causing an approximately $20 \%$ decrease of the feed temperature to the value of $200{ }^{\circ} \mathrm{C}$, the hydrogen conversion in the reactor system dramatically drops and the reaction of ammonia synthesis is practically terminated. The occurrence of this phenomenon in the investigated system leads to its further examination.

Detailed simulations of the presented system were carried out in order to evaluate the effect of the selected inlet parameters on the reaction conditions. Fig. 3 presents the locus of the steady states outlet temperatures of products, the molar fractions of ammonia from individual reactor beds and the required heat removal in the refrigeration unit for different fresh feed temperatures of the reactant mixture. When the temperature control system fails and the operation feed temperature is decreased by $20 \%$, to $200{ }^{\circ} \mathrm{C}$, the reaction conditions change significantly. The reactor outlet temperature is decreased from ca. $500{ }^{\circ} \mathrm{C}$ to ca. $200{ }^{\circ} \mathrm{C}$ (Fig. 3a) indicating the termination of the reaction. The termination of the reaction is confirmed by the analysis of the composition of the reactor segments outlet streams depicted in Fig. 3b. The molar fraction of ammonia is constant in the reactor beds outlet streams what means very low ammonia production in the reactor system. Also the required heat removal in the refrigeration system decreases considerably (Fig. 3c). When the temperature control failure is corrected, the fresh feed temperature is set back to $250{ }^{\circ} \mathrm{C}$. However, the reaction conditions remain in a steady state located on the lower solution branch and a new reactor start-up is required.

It is important to point out that the area between the higher and lower solution branches consists of the unstable steady states. If the reaction system is forced by process variable deviation to change its steady state to an unstable steady state, the reaction conditions stabilize in a stable steady state located on the higher or lower solution branch depending on the value and duration of the deviation. The ammonia synthesis modelling in Aspen HYSYS v8.4 environment was unable to identify these unstable steady states which were presented by Labovská et al. (2014).

Similar conclusion was obtained by the HAZOP analysis of the process variable "pressure". The design operation pressure is $20 \mathrm{MPa}$ in this case study. A typical process variable deviation created by a conventional HAZOP study would be a combination of the guide word "less" and the process variable "pressure" resulting in "lower pressure" than a design intent. Fig. 4 shows the locus of the steady states outlet temperatures of products from individual reactor beds for different pressure of the reactant mixture. The operation pressure drop of $25 \%$ causes gradual decrease of the reactor beds outlet temperature of ca. $5 \%$ from the design operation point. The operation pressure drop of $40 \%$, to $12 \mathrm{MPa}$, causes the reactor beds outlet temperature decrease of ca. $50 \%$ from the design operation point. After returning the operation pressure in the reactor to the desired operating point of $20 \mathrm{MPa}$, the ammonia synthesis process remains in the lower steady state and a new reactor start-up is required. These consequences are unlikely to be detected by a conventional HAZOP analysis. Therefore, the performance of a model-based HAZOP study is necessary to avoid overlooking nonlinear process behaviour and its possible hazard consequences.

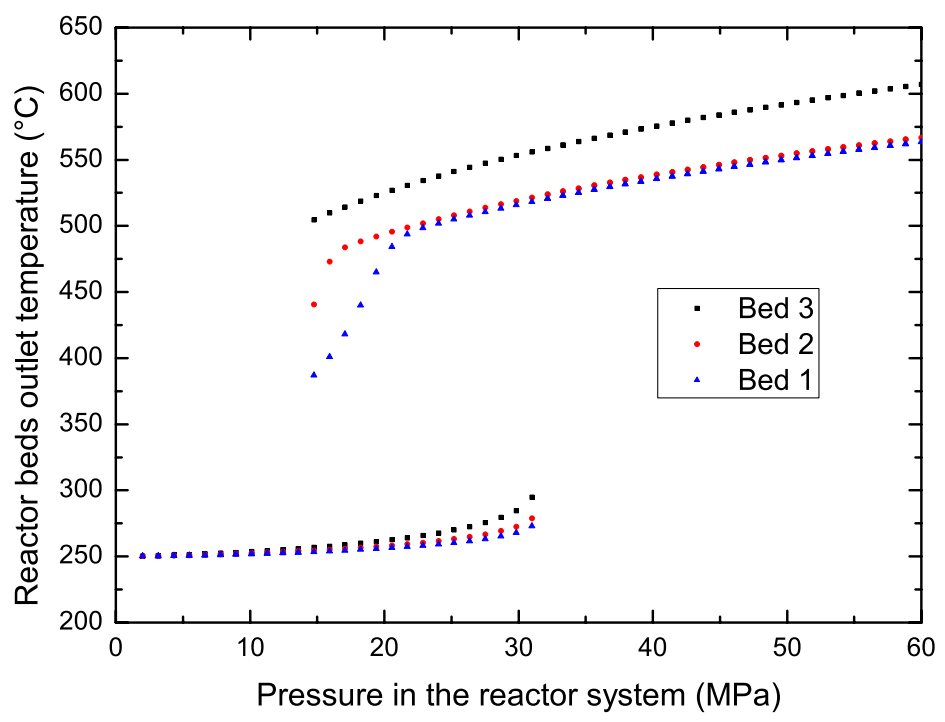

Fig. 4. Reactor beds outlet temperature dependence on the fresh feed pressure (triangles - bed 1, circles - bed 2, squares - bed 3). 


\section{Conclusions}

In this paper, an attempt to propose an appropriate mathematical model using the Aspen HYSYS v8.4 simulation environment was done. A mathematical model suitable for the identification and accurate prediction of nonlinear behaviour of chemical productions is the key component in a model-based HAZOP study. The case study was focused on the investigation of multiple steady states present in an ammonia synthesis fixed-bed reactor system. In the analysed chemical production, the feed temperature decrease to approximately $200{ }^{\circ} \mathrm{C}$ led to significant changes of the stable steady state of the reactor system. The reactor system outlet temperature dramatically dropped (from ca. $500{ }^{\circ} \mathrm{C}$ to ca. $200^{\circ} \mathrm{C}$ ) causing a decrease of the reaction rate which resulted in very low reaction conversion. After the feed temperature was returned to its original value of $250{ }^{\circ} \mathrm{C}$, the reactor system remained in the lower steady state. Therefore, a new reactor start-up procedure had to be carried out.

From the chemical engineering point of view, a reaction system can be operated in different regimes (temperature, pressure, conversion, etc.) under the same conditions of feed stream. From the process safety engineering point of view, switching between different steady states can lead to a dangerous event. As it was shown, a failure of a single parameter (the inlet temperature or the reactor pressure control) can cause operation regime change of the reaction conditions in the presented reactor system. Knowledge of the multiple steady states phenomena is crucial for inherently safer design as well as for stable and safe operation of ammonia synthesis. Nonlinear character of the presented system should be also considered in the design of process control.

\section{Acknowledgement}

This work was supported by the OP Research and Development of the project University Science Park STU Bratislava, ITMS 26240220084, co-financed by the Fund of European Regional Development.

\section{References}

De Rademaeker E, Suter G, Pasman HJ, Fabiano B (2014) Process Safety and Environmental Protection 92: 280-291.

Dunjó J, Fthenakis V, Vílchez JA, Arnaldos J (2010) Journal of Hazardous Materials 173: 19-32.

Eizenberg S, Shacham M, Brauner N (2006) Journal of Loss Prevention in the Process Industries 19: 754-761.

Froment GF, Bischoff KB (1990) Chemical Reactor Analysis and Design. Wiley, New York.

Jeerawongsuntorn C, Sainyamsatit N, Srinophakun $\mathrm{T}$ (2011) Journal of Loss Prevention in the Process Industries 24: 412-419.

Kang B, Lee B, Kang K, Suh J, Yoon E (1999) Expert Systems with Applications 16: 183-195.

Khan FI, Abbasi SA (1997) Journal of Loss Prevention in the Process Industries 10: 333-343.

Kletz TA (1997) Reliability Engineering \& System Safety 55: 263-266.

Labovská Z, Labovský J, Jelemenský L, Dudáš J, Markoš J (2014) Journal of Loss Prevention in the Process Industries 29: 155-162.

Labovský J, Švandová Z, Markoš J, Jelemenský L' (2007) Chemical Engineering Science 62: 4915-4919.

Labovský J, Švandová Z, Markoš J, Jelemenský L' (2007) Journal of Loss Prevention in the Process Industries 20: 230-237.

Morud J, Skogestad S (1998) AIChE Journal 44: 888-895.

Srinivasan R, Dimitriadis VD, Shah N, Venkatasubramanian V (1997) Computers \& Chemical Engineering 21, Supplement: S905-S910.

Venkatasubramanian V, Vaidhyanathan R (1994) AIChE Journal 40: 496-505. 